\title{
PRESENCIA DE CERAMICA COLONIAL MEXICANA EN ESPAÑA
}

\author{
Ma Concepción García Sáiz,
} JosÉ Luis BARrio MOYA

Entre los muchos campos de investigación americanista que esperan despertar el interés de los estudiosos, el de la cerámica colonial es uno de los más tristemente olvidados, a pesar de que su conocimiento exhaustivo aportaría numerosos datos para un mejor conocimiento histórico de este periodo. Incluso en lo que se refiere al virreinato de la Nueva España, lo desconocido es muy superior a lo conocido, y ello pese a la existencia de la ponderada cerámica de "Talavera de Puebla", como se ha dado en denominar tradicional (pero erróneamente) a la realizada en Puebla de los Ángeles. En conjunto, las obras realizadas por los talleres poblanos vienen disfrutando habitualmente de una atención que, como mínimo, sería necesario prestar a las restantes áreas cerámicas del virreinato. ${ }^{1}$ En muchos casos, algunos estudios documentales y estilísticos, que por su calidad e imporportancia debieran haber servido de acicate para abrir decisivas líneas de investigación, se han convertido en lugares comunes, empleados arbitrariamente con una intención de generalización que no tuvieron en su origen. ${ }^{2}$ En este sentido está claro que, como ya se ha reclamado en más de una ocasión, ${ }^{3}$ la realización de excavaciones arqueológicas dedicadas a ámbitos de ocupación colonial es la primera y más urgente medida que hay que tomar. Ello permitirá establecer un conjunto de tipologías y secuencias cronológicas imprescindibles y difíciles de determinar cuando sólo nos movemos en el terreno del análisis estilístico.

Ante este estado de la cuestión es evidente que adquieren especial importancia todos los datos aportados por otras disciplinas que contribuyan a clarificar el tema. En este sentido las noticias tomadas de los documentos

1 Es evidente que la prolifetación de publicaciones como la de Flotencia Muller, "Es tudio de la cerámica hispánica y moderna de Tlaxcala.Puebla", en Colección Científica, 103, INAH, México, 1981, es el único medio para llegar a un verdadero conocimiento del tema.

${ }^{2}$ El trabajo de Diego Angulo, La cerámica de Puebla, Madrid, 1946, y los de Enrique Cervantes, Nómina de Loceros poblanos, México, 1933, y Loza blanca y azulejo de Puebla, 2 vols., México, 1939, supusieton en su momento una importante aportación, aunque ambos autores ya se enfrentaban a las dificultades aquí mencionadas.

3 Gonzalo López Cervantes, "Cerámica colonial en la ciudad de México", Colección Cientifica, 38, INAH, México, 1976 
oficiales, como tasaciones e inventarios, y las recogidas de las pinturas de la época, son especialmente significativas, a pesar de las muchas limitaciones con que se presentan ya que, mientras los papeles legales en la mayoría de los casos se limitan a proporcionar largas listas de "barros" o "vasijas", sin que éstos puedan ser relacionados con un objeto en concreto, la pintura colonial fundamentalmente dedicada a la temática religiosa, elude de forma sistemática el género del bodegón -que tan útil habría de sernos para este asunto.

Por esta serie de razones nos ha parecido de especial importancia el presentar este trabajo en el que se ponen en relación los documentos de la época con las piezas a las que se refieren y los lienzos que las reprodujeron - a ellas o a otras semejantes - en su momento.

Lo que podría parecer una feliz coincidencia no es sino el fruto de un continuado estado de alerta en torno de un tema que no parecía estar suficientemente definido hasta el momento: el de la correcta clasificación de una extensa colección de cerámica perteneciente a los fondos del Museo de América. Este importante conjunto, compuesto por cerca de un mi1lar de piezas, fue donado en 1884 al Museo Arqueológico Nacional por su última propietaria, la condesa viuda de Oñate, doña Josefa de la Cerda y Palafox. El 30 de junio de 1885 sus testamentarios habían realizado el correspondiente inventario de sus bienes y señalaban cómo "la colección de búcaros u objetos de cerámica antigua que según la cláustla 62 había de entregarse al Museo Arqueológico", no había sido tasada por expreso deseo de la difunta condesa. ${ }^{7}$ Cuando estos objetos pasaron a ser relacionados con el libro de registro ${ }^{5}$ del mencionado Museo ya se les hizo aparecer como procedentes de América y, concretamente, de México. Transcurrido más de medio siglo después de establecerse este legado, en 1941, se creó el Museo de América, y a él fueron destinados, entre otros muchos, estos objetos, exhibiéndose de forma provisional parte de ellos, en las salas que se le cedieron dentro de los locales del Museo Arqueológico, a la espera de su traslado definitivo a la sede del Museo de América, que habría de construirse. Una vez finalizada ésta, alli se llevaron y permanecieron en exposición tras un transporte poco afortunado, pues "Esta colección sufrió grandes desperfectos cuando la traslación del antiguo al nuevo museo, por efectos de un accidente" "Desde la fecha de su donación hasta la actua. lidad, diferentes piezas de la colección han figurado en numerosas exposi-

${ }^{4}$ Archivo Histórico de Protocolos de Madrid. Protocolo 35 416, fol. 2347-2348 vlto.

"Libro Inventario del Museo Arqueológico Nacional. Ms Archivo del Museo de América, Madrid.

"Ibidem Nota manuscrita en el margen izquierdo. 


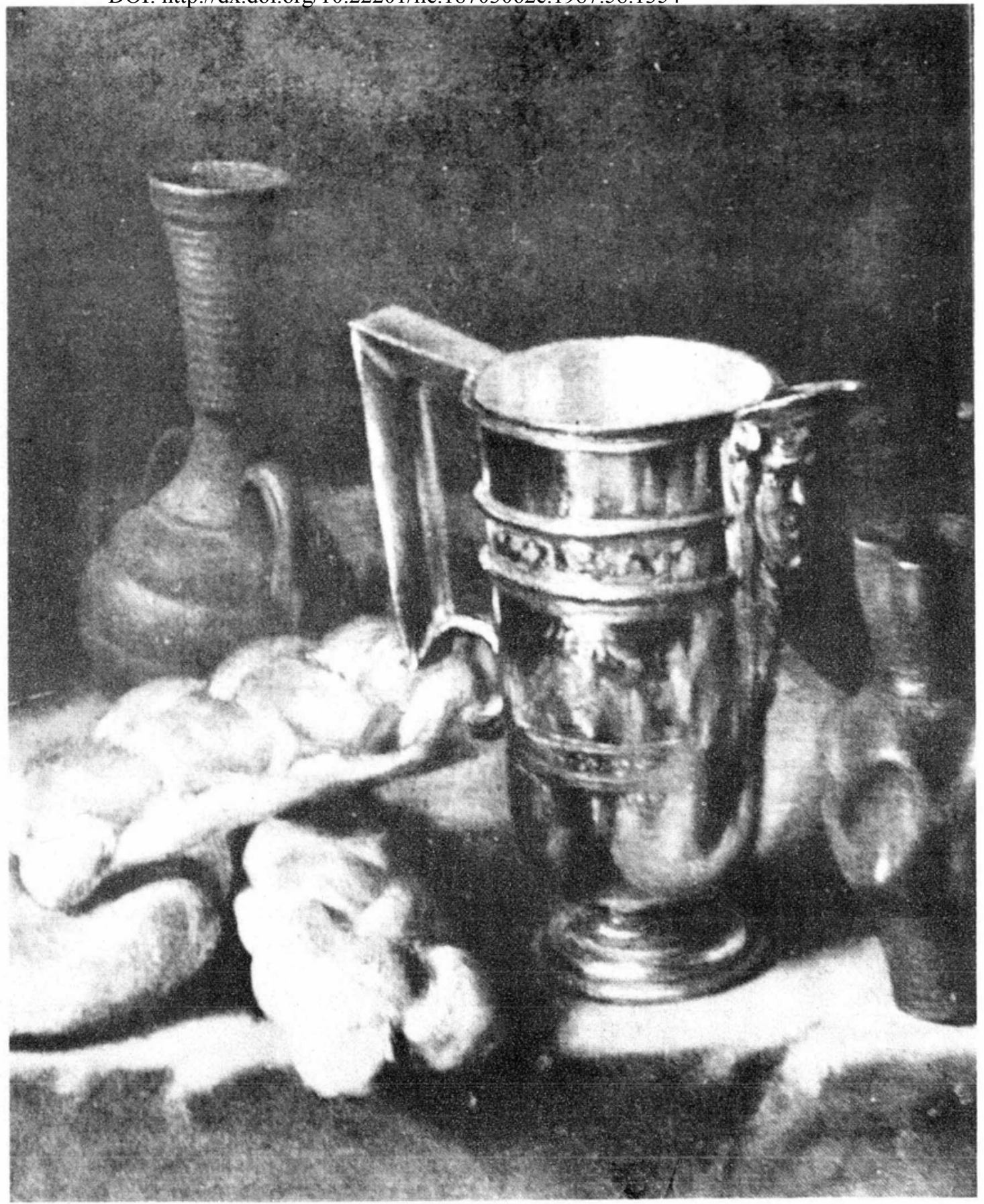

Figura 1. Francisco de Palacios (h. 1.620-1676). Bodegón con panes de trenza (detalle). Palacio Rohran (Austria). 
DOI: http://dx.doi.org/10.22201/iie.18703062e.1987.58.1354

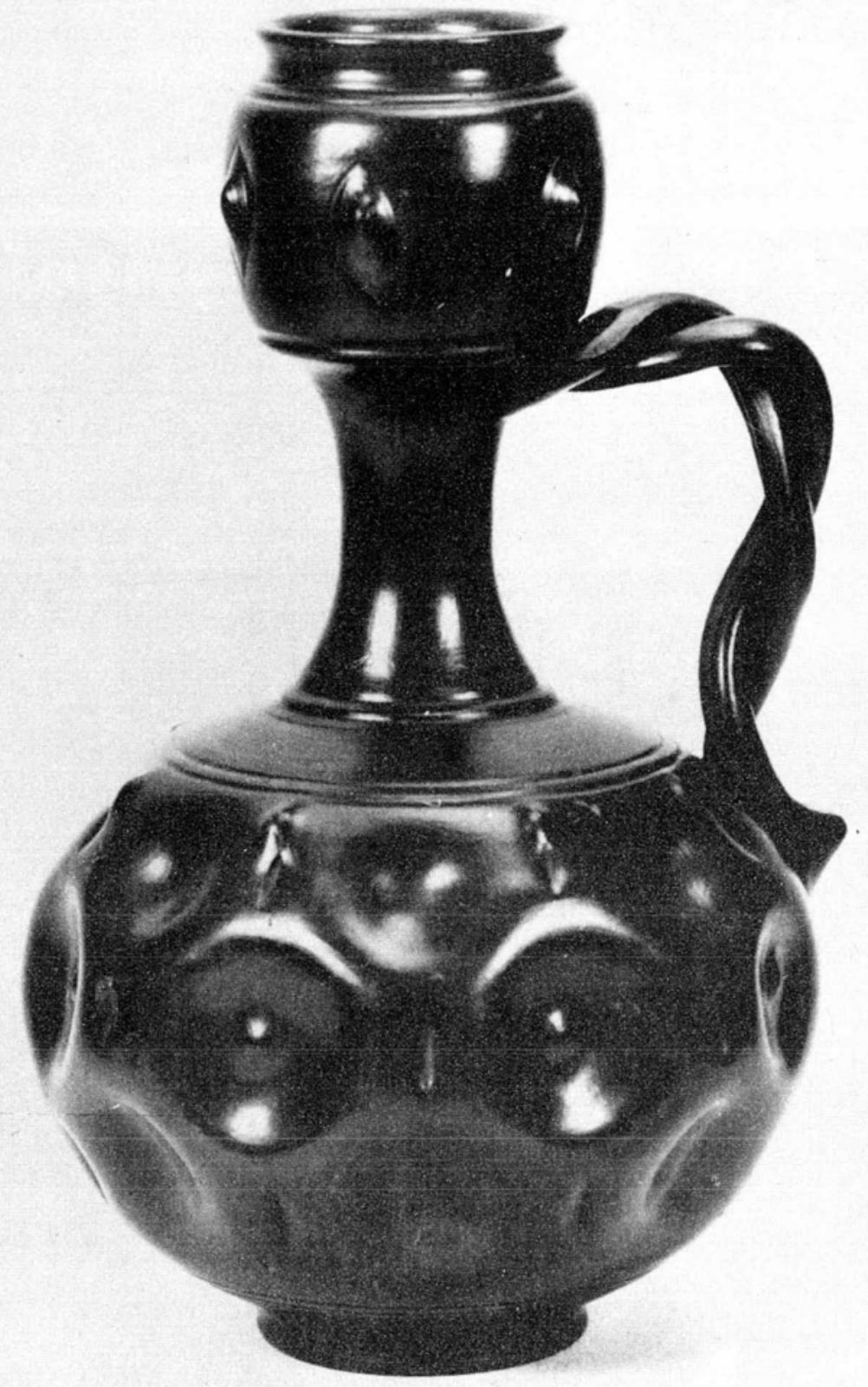

Figura 2. Museo de América. Madrid. $\mathrm{N}^{\circ} \mathrm{Invt}^{\circ}$.: 4.086 . 
DOI: http://dx.doi.org/10.22201/iie.18703062e.1987.58.1354

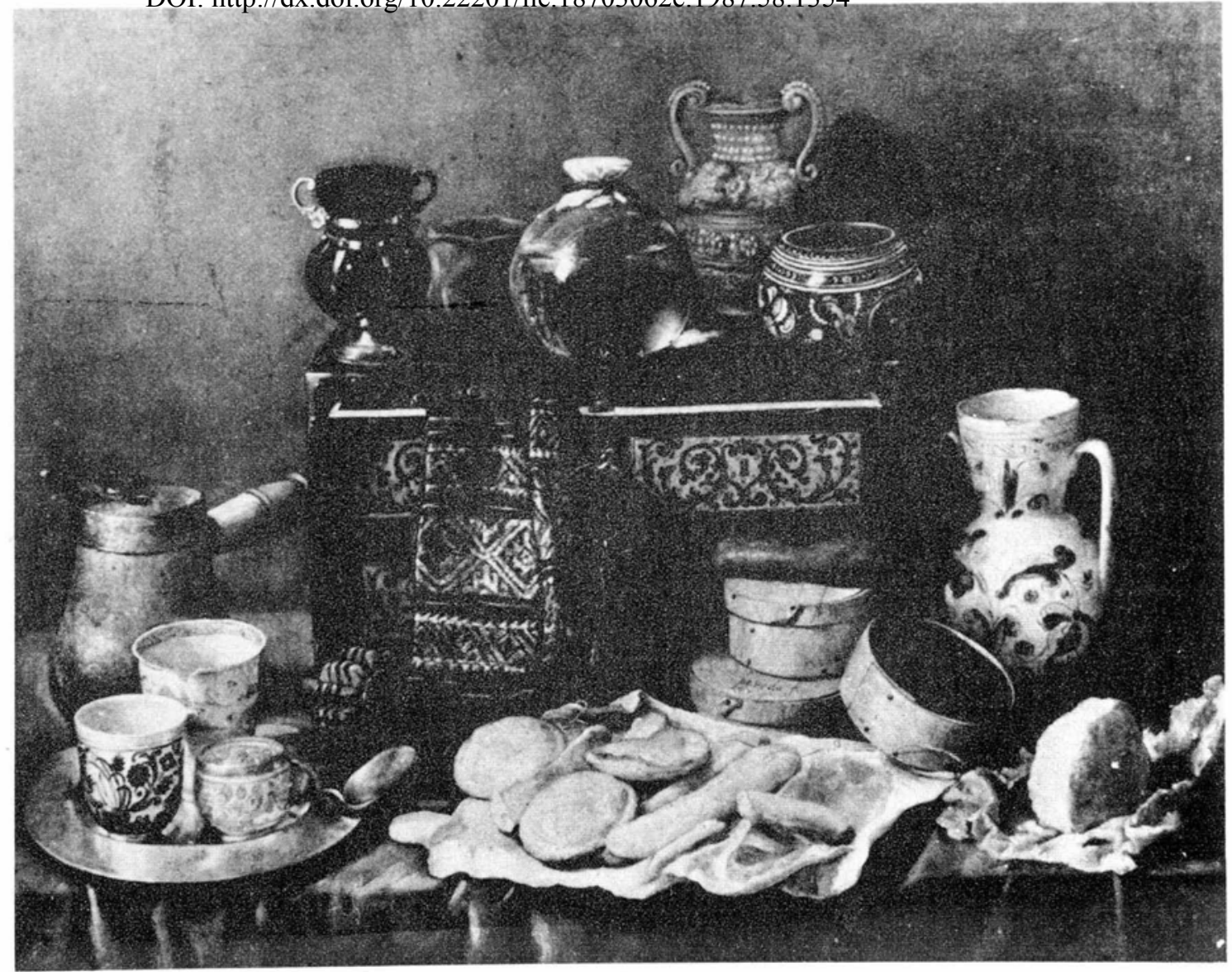

Figura 3. Antonio de Pereda $(1.611-1.678)$. Bodegón con papelera de ébano. Ermitage (Leningrado). 
DOI. http://dx.doi.org/10.22201/iie.18703062e.1987.58.1354

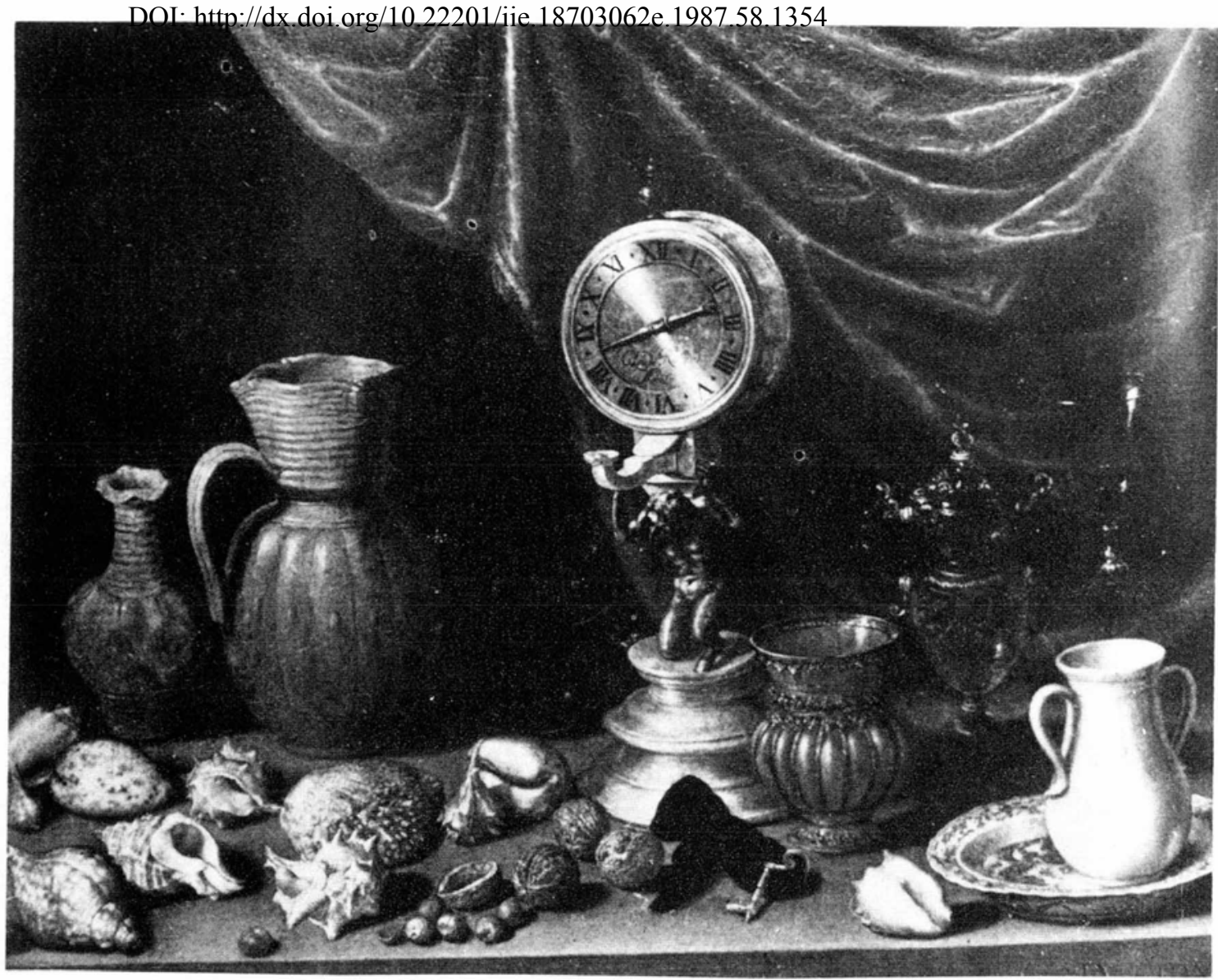

Figura 4. Antonio de Pereda. Bodegón del reloj. Museo Puchkin. Moscú. 
DOI: http://dx.doi.org/10.22201/iie.18703062e.1987.58.1354

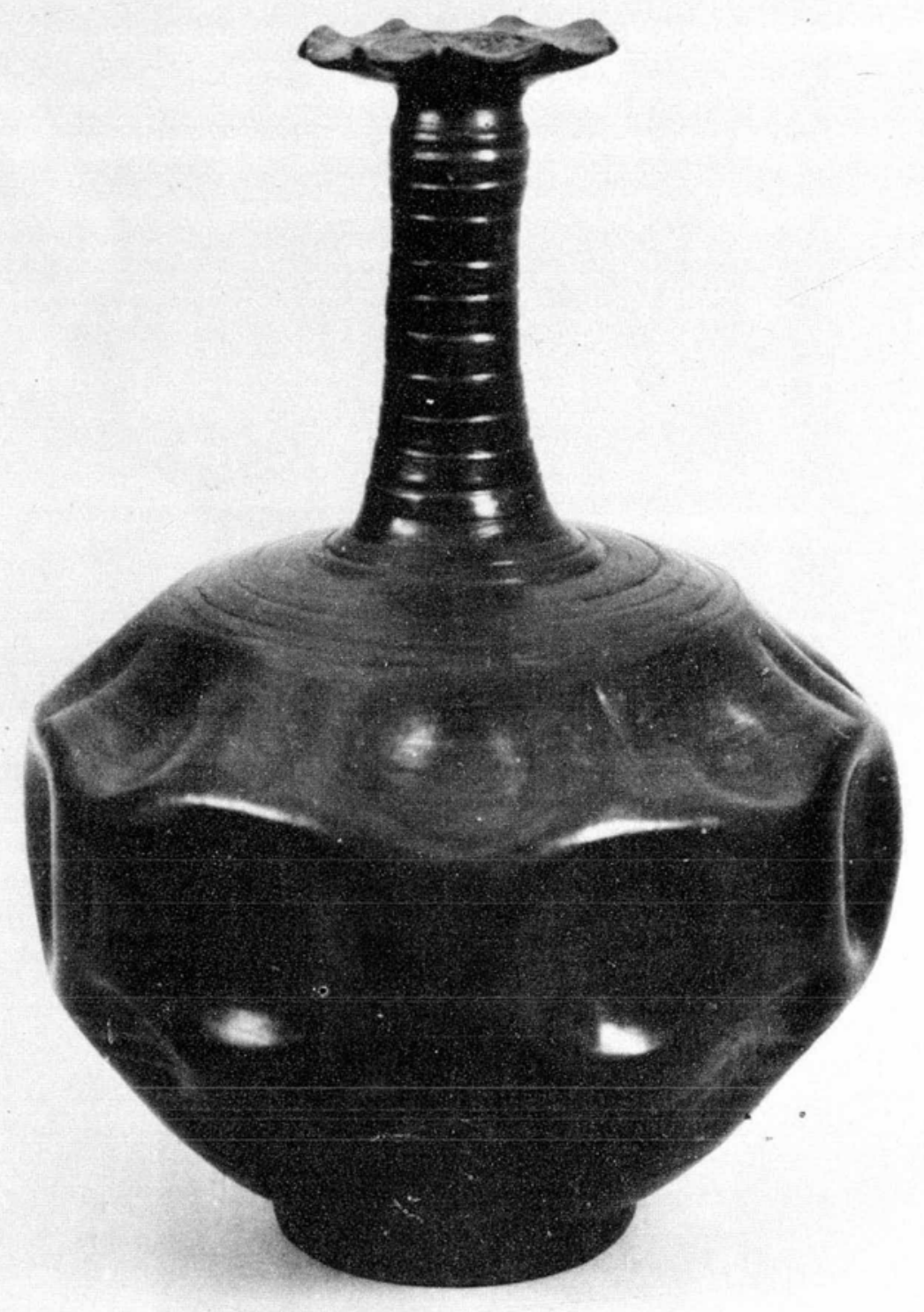

Figura 5. Museo de América. Madrid. $\mathrm{N}^{\circ}$ Invt $^{\circ} .: 4.053$. 


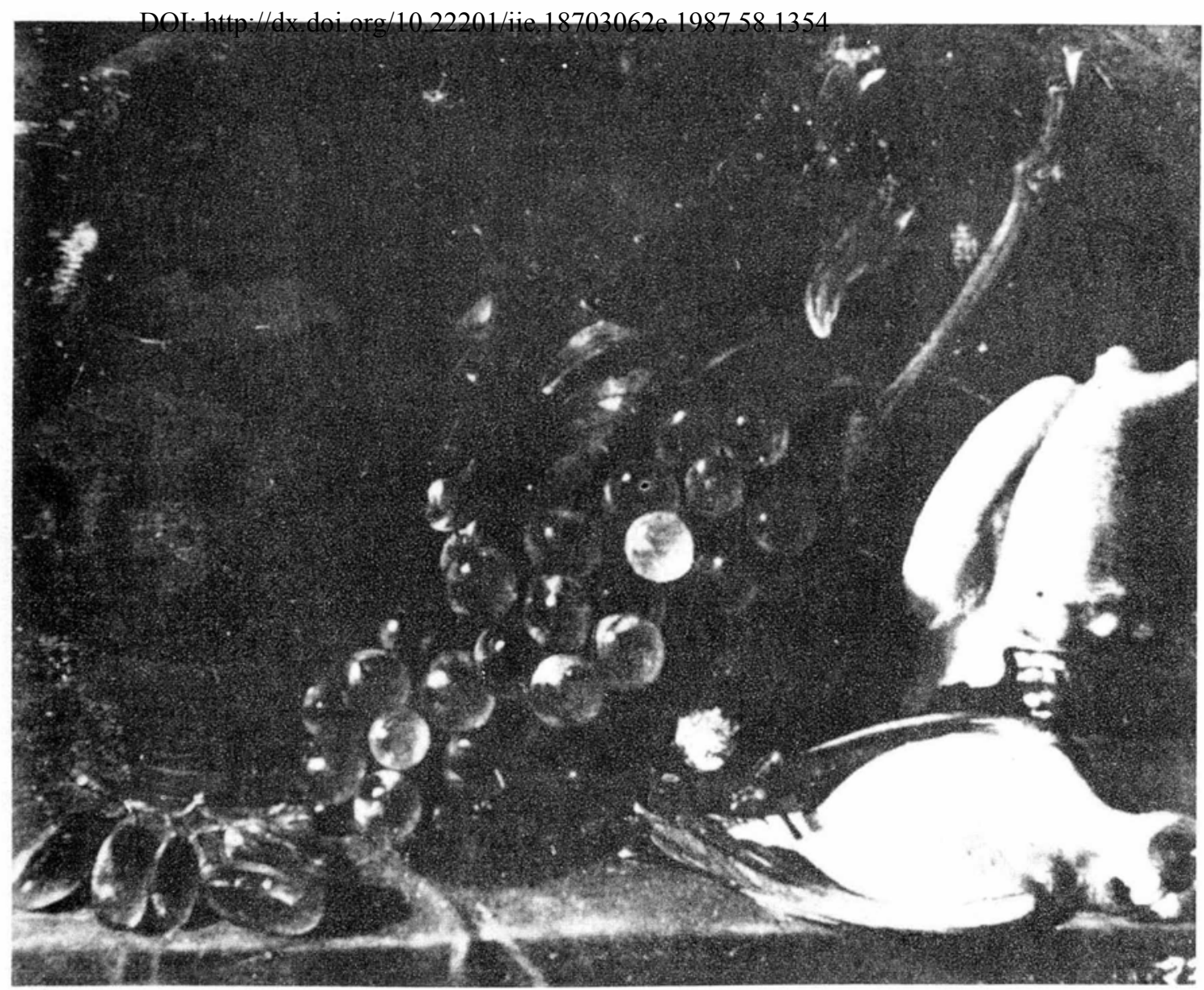

Figura 6. Juan Bautista Espinosa (S. XVIII). Bodegón. Museo Provincial. Córdoba. 
DOI: http://dx.doi.org/10.22201/iie.18703062e.1987.58.1354

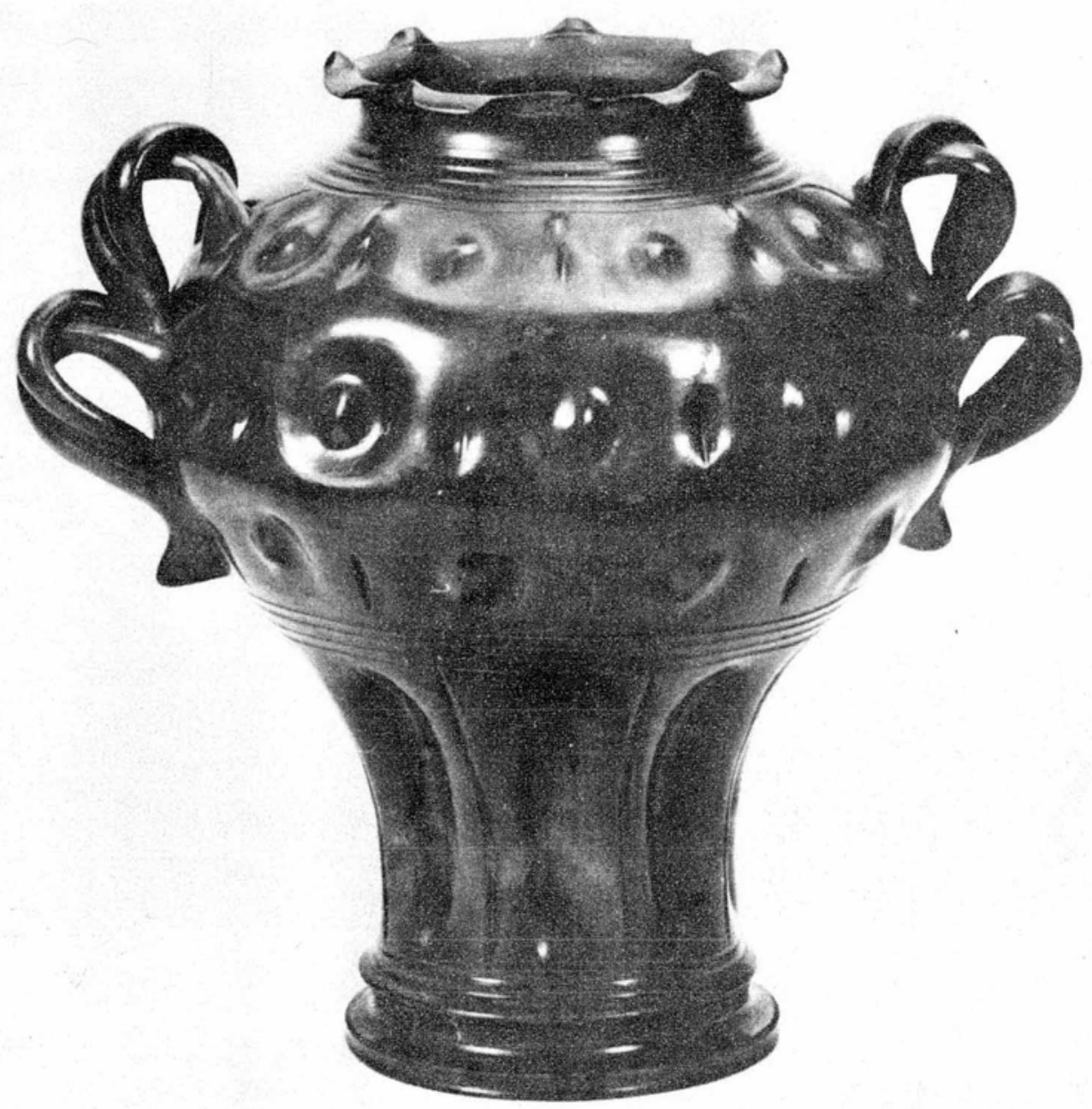

Figura 7. Museo de América. Madrid. $\mathrm{N}^{\circ}$ Invt $^{\circ} .: 4.031$. 


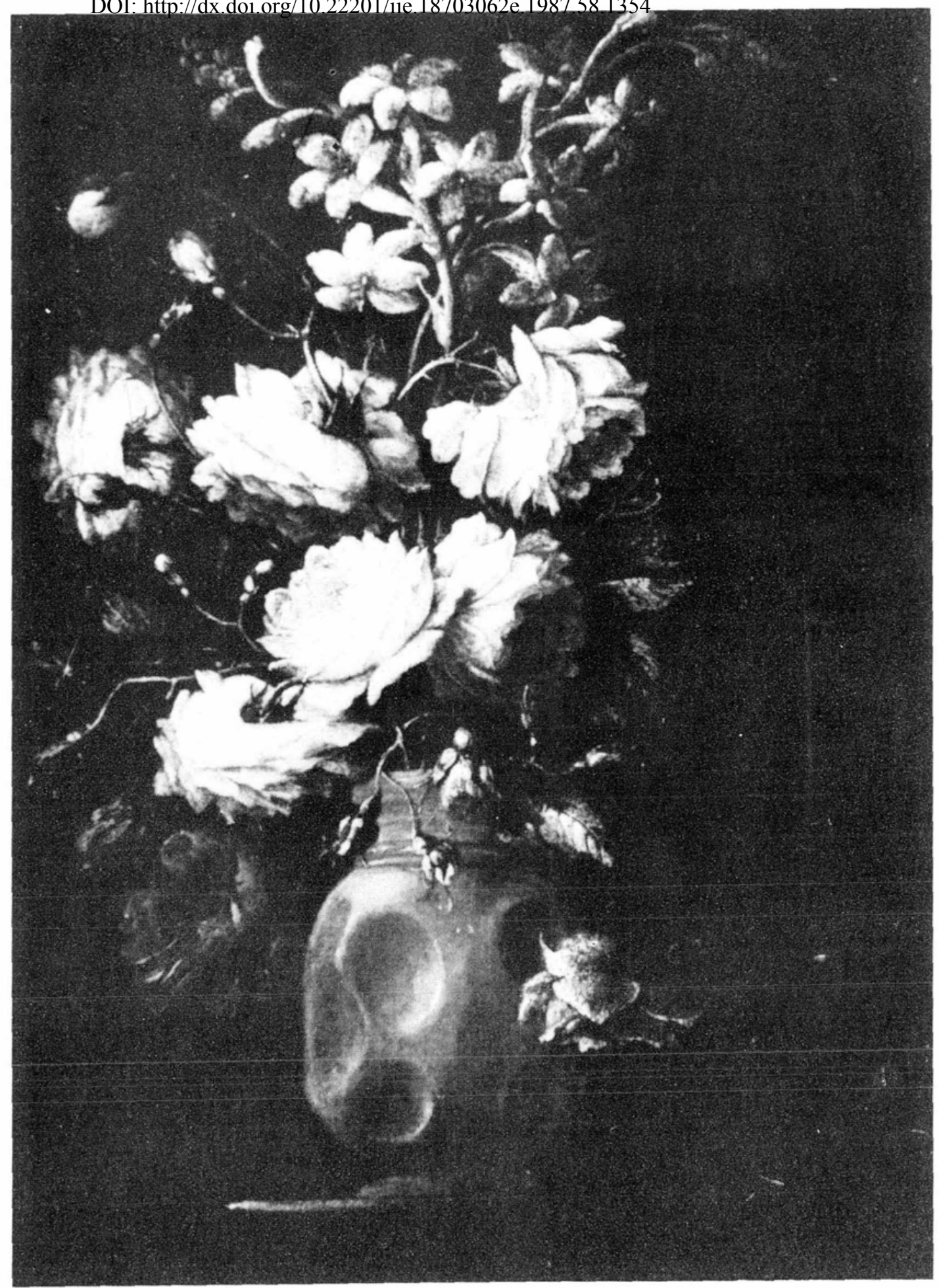

Figura 8. Andrea Belvedere $(1.652-1.732)$. Florero. Colección particular. Barcelona. 


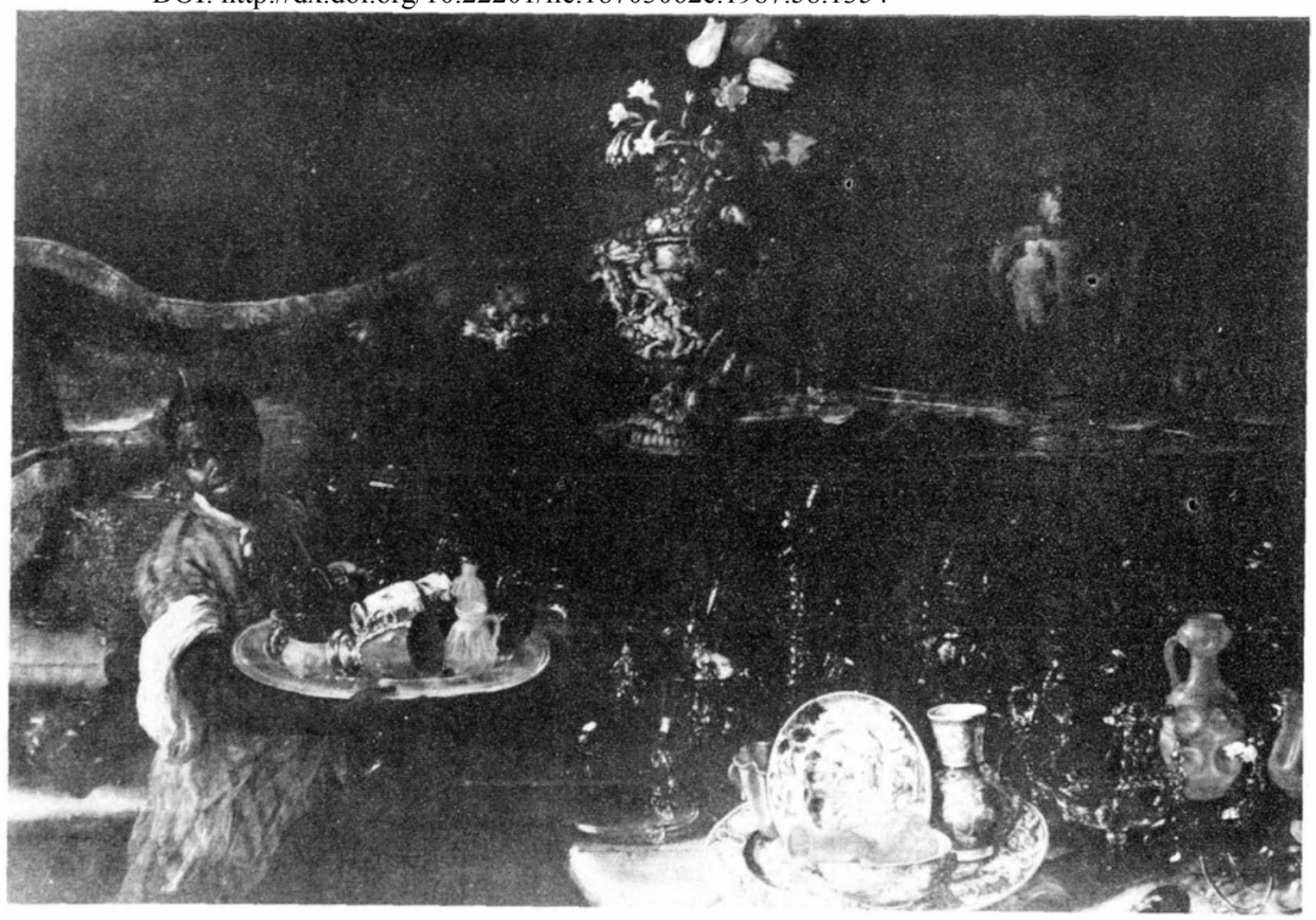

Figura 9. Giuseppe Recco $(1.34-1.694)$. Bodegón con criado negro. Casa Ducal de Medinaceli. Sevilla. 
DOI: http://dx.doi.org/10.22201/iie.18703062e.1987.58.1354

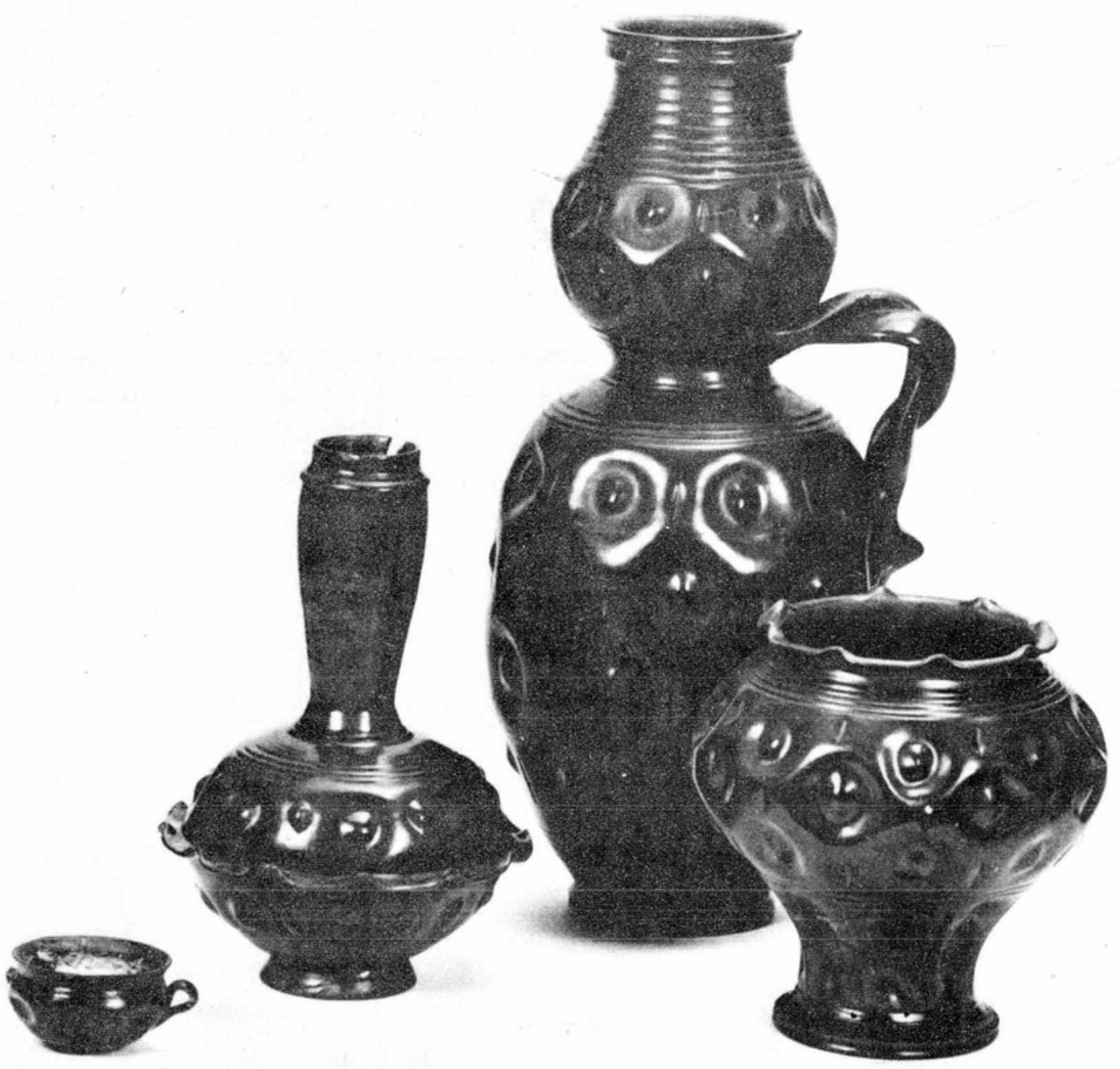

Figura 10. Museo de América. Madrid. $\mathrm{N}^{\circ}$ Invt $^{\circ} .: 4.543,4.100,4.672$ y 4.025. 


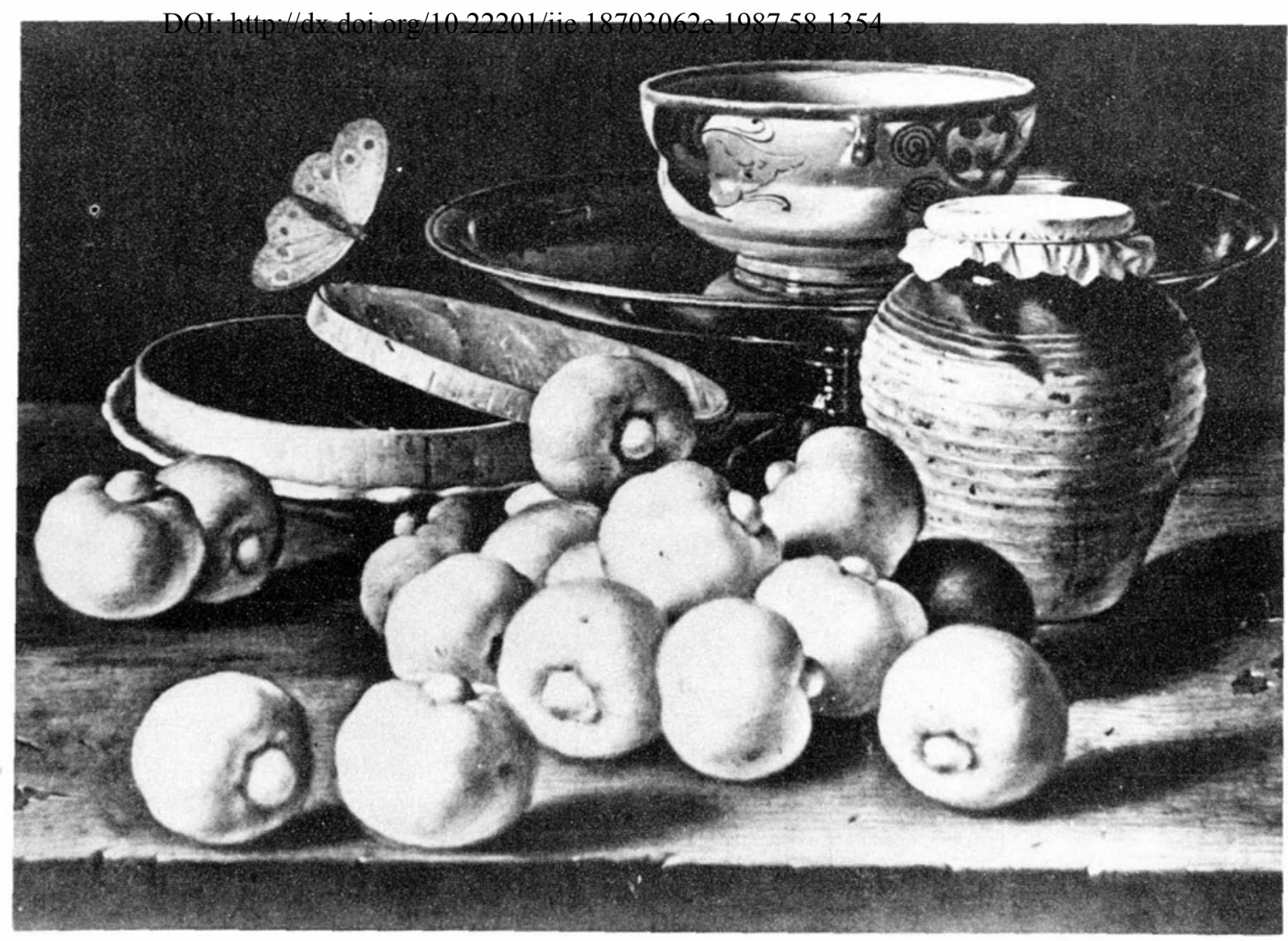

Figura 11. Luis Meléndez (1.716-1.780). Bodegón. Museo del Prado. Madrid. 
DOI: http://dx.doi.org/10.22201/iie.18703062e.1987.58.1354

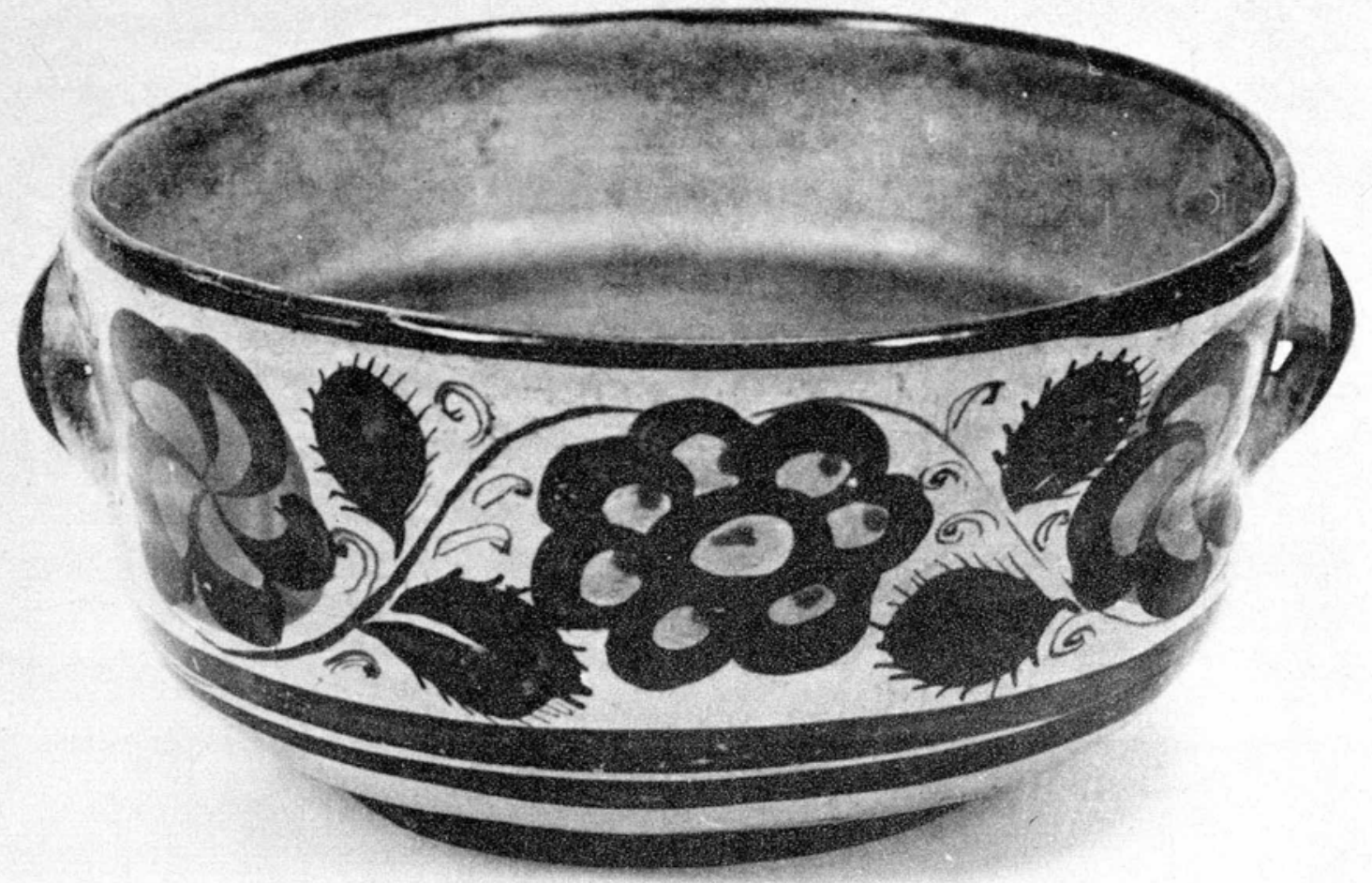

Figura 12. Museo de América. Madrid $\mathrm{N}^{\circ}$ Invt $^{\circ} .: 4.785$. 
ciones y han servido para ilustrar diversas publicaciones de carácter general; sin embargo, en la actualidad es cuando se ha emprendido su estudio particular. ${ }^{7}$

Lo que hoy nos interesa establecer es la historia de parte de esta colección, documentar el uso que de este tipo de cerámica se hacía en España, donde al parecer llegaba en elevado número, y mostrar de qué manera, como consecuencia de su presencia habitual en los ajuares de la nobleza peninsular, se introdujo en la pintura de artistas españoles, portugueses e italianos. Para aclarar el primer punto contamos con el inventario de la condesa de Oñate realizado tras su muerte en $1685 .^{8}$ En él encontramos por primera vez claras referencias a los "barros de guadalaxara de las Yndias", junto a otros negros de la misma zona y a un extenso número procedente de Chile. Es evidente que en este caso se hace referencia a los recipientes de cerámica roja pulida que se guardan en el Museo. No aparecen, sin embargo, los grandes tibores que también forman parte del conjunto legado por su descendiente, las magníficas piezas policromadas -tazas, vasos y platos - ni los diminutos vasos de "color rosáceo" a que se refiere el último inventario. ${ }^{9}$ Es de suponer que la rica colección familiar se fuera incrementando con el paso de los años, y durante el siglo XVIII debieron de añadirse la mayoría de las piezas no relacionadas en esta ocasión. Tal vez, como ya ha sido reseñado, ${ }^{10}$ le correspondió a otro miembro de la casa ocuparse de ello.

Estamos así ante las piezas denominadas como "barro bucarino" o "tierra sigilada" -esto último por su aparente semejanza con algunas de las variedades de la sigilata romana- a la que ya se referían los escritos del siglo XVII. Especialmente aquellos viajeros curiosos que, como la francesa condesa D'Aulnoy, se sorprendían ante el uso que de esta cerámica hacían las nobles españolas. Para comprender y compartir su asombro, nada mejor que seguir con detalle la minuciosa narración de su visita a la princesa de Monteleón en la casa que poseía en Madrid:

También algunas, en casa de la princesa, comieron tierra sigilada. Ya os hablé de la pasión que muchas ponen en mascar esta tierra. Suelen quedar opiladas: el estómago y el vientre se les hinchan y endurecen, y la piel se les pone amarilla como un membrillo. Quise probar esta golo-

${ }^{7}$ Este tema constituye la tesis doctoral de María de los Ángeles Albert de León, en cut'so de realización.

${ }^{8}$ Atchivo Histótico de Ptotocolos de Madtid. Ptotocolo 11 162, fol 158-168 y fol 295-304

${ }^{9} \mathrm{Op}$, cit.

${ }^{10}$ Museo de América Guía de su instalación provisional, Madrid, 1944, p. 73 
sina tan estimada y tan poco estimable, y seguro que preferiría comer asperón que tierra sigilada. No obstante, si se pretende ser agradable a estas damas, es preciso regalarles algunos búcaros, que ellas denominan barros, $y$ frecuentemente los confesores no les ponen otra penitencia que la privación de pasar un día sin probar aquella tierra. Que, a juicio de muchas, tan excelentes y numerosas cualidades reúne. . Cura ciertas enfermedades, y en un vaso de tierra sigilada se descubre cualquier bebida venenosa. Yo tengo uno que hace malo el vino y riquísima el agua. Ésta parece que hierve cuando se la ve agitarse y retemblar. (No sé si es propio lo que digo). Pero después de algún tiempo, no largo, el vaso queda vacío. Tan porosa es la tierra de que está hecha, y huele muy bien. ${ }^{11}$

Ya sea con destino a este uso tan "snob" o para ser utilizadas habitualmente como cualquier otro recipiente de barro, lo cierto es que este tipo de cerámica tuvo un lugar reservado en muchos bodegones pintados a lo largo del siglo XVII, especialmente en la segunda mitad. Ya en 1648 el español Francisco de Palacios incluye una de ellas en su Bodegón con panes de trenza (Palacio Rohran, Austria), ${ }^{12}$ y Antonio de Pereda recurre en repetidas ocasiones a estas piezas para componer sus naturalezas muertas. ${ }^{\mathbf{1 3}}$ Más avanzado el siglo, pintores italianos como Giuseppe Recco y Andrea Belvedere dejan nuevos ejemplos en sus lienzos del interés por estos objetos. Recco les concede la máxima importancia al convertirlos en protagonistas de sus "Floreros" (Barcelona y Capodimonte), ${ }^{14}$ mientras Belvedere nos crea una especial inquietud al mostrarnos en su Bodegón con criado negro (Casa Ducal de Medinaceli) un conjunto que se nos antoja idéntico al descrito por el inventario de la duquesa, pues allí también se amontonan las cerámicas rojas, negras, el cristal de Venecia y los cocos guarnecidos de plata. ${ }^{15}$ La circunstancia de que el conde de Oñate fuera virrey de Nápoles y de que allí fuera pintado este cuadro en 1679, más de veinte

${ }^{11}$ Condesa D'Aulnoy, Viaje por España en 1679 a 1680 y Cuentos Feéricos, Madrid, 1962, vol. I, p. 184.

12 Pintura española de los siglos XVI al XVIII en colecciones centroeuropeas Catálogo de la Exposición, Museo del Prado, Madrid, Diciembre-Enero, 1982, pp. 92-93.

${ }_{13}$ Antonio de Pereda (1611-1678) y la pintura madrileña de su tiempo Catálogo de la Exposición, Ministerio de Cultura, Madrid, Diciembre-Enero, 1978-79.

14 Pintura Napolitana. De Caravaggio a Giordano. Catálogo de la Exposición, Museo del Prado, Madrid, Octubre-Diciembre, 1985, pp. 86-87 y $256-57$.

${ }_{15}^{5}$ El apéndice documental que se incluye al final de este trabajo no ptesenta el total de los inventarios, pues hubiera sido demasiado extenso y poco útil en esta ocasión En consecuencia, sólo se han transcrito las referencias a piezas americanas específicamente reseñadas como tales en el documento. Sin embatgo, hay que señalar que en la importante colección aparecen numetosas piezas de cerámica española y portuguesa, así como porcelanas chinas, vidrios italianos y otros objetos procedentes de diferentes partes del mundo, incluidas las Indias Orientales. 
años después de que el noble abandonata su cargo, no nos permite asegurar una relación directa entre la pintura y la casa de Oñate, aunque nos sintamos inclinados a hacerlo. Al menos podemos constatar que si no fue ésta la colección representada por Belvedere, lo fue otra de muy semejantes características. ${ }^{16}$

Por último, señalemos la presencia de esta cerámica también entre la nobleza portuguesa donde, en opinión de la citada francesa, los gustos eran muy semejantes a los españoles. Allí también quedaton pruebas pictóricas de ello, ya que la propia infanta de Portugal se hizo retratar acompañada por "dos cestos con flores y varios jarritos de tierra sigilada, que se come como una golosina en España y Portugal, a pesar de ser muy poco sabrosa"."1i

La costumbre no pareció perderse con rapidez y a mediados del siglo XIX sigue asombrando a los extraños que la conocen. De nuevo un francés, Théophile Gautier, es quien se extiende en su explicación añadiendo nuevos detalles y haciendo una directa referencia a la procedencia americana de las piezas:

Los búcaros son una especie de jarros de barro rojo de América, muy parecido al de que están hechos los tubos de las pipas turcas; los hay de todas las formas y tamaños, algunos tienen unos cantos dorados y flores pintadas toscamente. Como ya no se fabrican en América, los búcaros empiezan a ser raros, y dentro de algunos años serán tan escasos y fabulosos como el viejo Sèvres; entonces los tendrá todo el mundo. Cuando se quiere utilizar los búcaros colocan siete u ocho sobre el mármol de los veladores o de las rinconeras, se les llena de agua y se sienta uno en un sofá esperando que produzcan su efecto y poder saborear el placer con el conveniente recogimiento. La arcilla se oscurece, el agua traspasa los poros, y los búcaros no tardan en rezumar y en espaciar un aroma que se asemeja al del yeso mojado o al de una cueva húmeda que no se hubiera abierto desde mucho tiempo atrás. La transpiración de los búcaros es tal que al cabo de una hora la mitad del agua se ha evaporado; la que queda en el cacharro está fría como el hielo y tiene un sabor a cisterna bastante repugnante, pero que encuentran delicioso los aficionados. Media docena de búcaros son suficientes para impregnar el aire de un gabinete de tal humedad, que no podéis dejar de ad. vertirla al entrar: es una especie de baño de vapor frío. No contentas

${ }^{16}$ Aunque no poseemos todavía datos más numerosos sobre la localización de este tipo de piezas en inventatios españoles, sí podemos añadir el ejemplo de algún otro, como es el que se realiza a la muerte de don Isidoro Garma de la Puente, en 1717 Este personaje, "Caballero de la Orden de Calatrava, del Consejo SM , Regidor Perpetuo de Segovia y Marqués de Pesadilla, poseía bartos de Guadalajara, de sigilata, de Chile y de las Yndias" (A.H. P., Prot. 14.522, fol. 521-586).

17 Condesa D'Aulnoy, op. cit., t I, p. 162. 
con beber el agua y aspirar su perfume, algunas personas mascan peda. citos de búcaro, los reducen a polvo y acaban tragándoselos. ${ }^{18}$

Hasta qué punto esta misma costumbre fue practicada en el Virreinato, lo desconocemos por completo, a pesar de la opinión de Romero de Terreros en sentido afirmativo ${ }^{19}$ y de quienes repiten su teoria. Nos faltan pruebas como las aquí expuestas pues, curiosamente, desconocemos si existe alguna colección semejante a la del Museo de América y también ignoramos si ha sido localizado algún documento que se refiera a esta cerámica como de Guadalajara. Asimismo, la pintura colonial, como ya recordábamos, es poco explícita en estos temas y habrá que esperar a la segunda mitad del siglo XVIII para que los pintores de "castas" nos of rezcan el interior de algunas cocinas coloniales, en las que figuran cacharros de muy diferente calidad. Demasiado tarde para relacionarlo con esta parte de la colección, en el caso de que aparecieran piezas que pudiéramos identificar con ella.

De nuevo es la pintura española, esta vez de mano del dieciochesco Luis Meléndez, la que nos da la pauta para comprobar que las piezas policromadas, que engrosaron posteriormente la Colección Oñate, siguieron mereciendo la atención de los peninsulares, quienes continuaron contribuyendo a su difusión. Los magníficos bodegones que posee el Museo del Prado ${ }^{20}$ así lo atestiguan, lo mismo que el perteneciente a la Colección Oetker de Bielefeld. ${ }^{21} \mathrm{Al}$ mismo tiempo, algunas piezas de las mismas caractcrísticas van apareciendo en España poco a poco, como prueba evidente de su nota. ble presencia a lo largo de dos siglos.

\section{Tasación de barros ${ }^{22}$}

- Mas dos jarras de guadalajara negra y la una rompida en veinte y cuatro reales, 24 rs.

- Mas los barros de tres escaparates grandes con sus bidrios christalinos grandes y chicos de gadalaxara de las yndias y otros en que ay ciento y

18 T. Gautier, Viaje por España. 1840-1845, Madrid, 19.., pp. 107-108.

19 Francisco Rometo de Tetretos, Las antes industriales en la Nueva España. México, 1943 , p. 154

${ }^{20}$ Luis Carlos Gutiérrez Alonso, "Precisiones a las cerámicas de los bodegones de Luis Meléndez", Boletín del Museo del Prado, t. IV, No 12, Septiembre-Diciembre, 1983, pp. 162-166.

${ }^{21}$ Reproducido en Luis Meléndez. Bodeguista español del siglo XVIII. Catálogo de la Exposición, Museo del Prado, Madrid, Diciembre-Eneto, 1983, p. 36

2: Selección de la tasación hecha por Manuel de Villanueva en Madrid el 28 de matzo de 1685 
sesenta y un barros de guadalaxara a seis reales uno con otro hazen nobecientos y sesenta y seis reales, 966 rs.

- Mas treinta y dos barros de chile a cinco reales de plata cada uno hazen ducientos y quarenta reales, 240 rs.

- Mas tres jarrones de Guadalaxara, 72 rs.

- Mas dos barros de chile grandes en cinco reales de a ocho ambos hazen sesenta, 60 rs.

- Mas nobenta y quatro barros negros de guadalaxara de las Yndias chico con grande a cinco reales de vellon montan quatro cientos y setenta reales, 470 rs.

- Mas ciento y veinte y un barros de chile grandes y pequeños uno con otro a seis reales montan setecientos y veinte y seis reales, 726 rs.

- Mas cinco barros de guadalaxara a quatro reales de vellon hazen veinte reales, $20 \mathrm{rs}$.

- Mas otra tinaja de chile en ochenta y ocho reales, 88 rs.

- Mas nobenta y tres barros de guadalaxara de las Yndias las cincuenta $\mathrm{y}$ uno coloradas y los cuarenta y dos negros que a seis reales cada uno con otro hazen quinientos y cinquenta y ocho reales, $558 \mathrm{rs}$.

- Mas doze barros de lo mismo mas pequeños a dos reales de plata montan treinta y seis reales, $36 \mathrm{rs}$.

- Mas veinte barros mayores de guadalaxara colorados a seis reales de plata cada uno hazen ciento y ochenta reales, $180 \mathrm{rs}$.

- Mas treinta y seis barros de chile de diferentes tamaños a seis reales cada uno hazen ducientos y diez y seis rs., 216 rs.

- Mas quinze barros chicos de chile a tres reales cada uno hazen quarenta y cinco, 45 rs.

- Mas un barro grande de chile en veinte y quatro reales, 24 rs.

- Mas seis barros pequeños de chile blancos a tres rs. cada uno hazen diez y ocho reales, $18 \mathrm{rs}$.

Tasación de barros con adornos de plata ${ }^{23}$

- Un barro grande de chile guarnecido de plata de feligrana con tapador, assas y pie y diferentes ojas sobrepuestas, todo de filigrana quinientos reales de plata, 500 rs.

- Ottro barro de chile pequeño con pie, assas, tapador y claveles de feligrana de plata bale ziento y sessenta reales de plata, $160 \mathrm{rs}$.

${ }^{23}$ Selección de la tasación hecha de los bartos con adornos de plata por Gabriel Mayers el 12 de mayo de 1685 . 
- Ottro barro de chile de gollete angosto con pie, assas, tulipanes y tapador, todo de feligrana de plata bale ziento y setenta y seis reales de plata, 176 rs.

- Ottro barro de chile con pie, assas, animales y tapador de ojas todo de feligrana de plata bale ziento y sessenta reales de plata, 160 rs.

- otro barro de chile con pie, assas, rossas y tapador de feligrana de plata vale ziento y beinte y ocho reales de plata, 128 rs.

- otro barro de chile en forma de garrafilla con pie, assas, rossas y tapador de feligrana de plata bale ziento y beinte y ocho reales de plata, 128 rs.

- ottro barro de chile pintado de colores con pie, listas y asas de plata bale ochenta reales de plata 80 rs.

- ottro Barro de chile con pie, assas, rossas, claveles y tapador de feligrana de plata bale doszientos rs. de plata, 200 rs.

- ottro barro de chile guarnecido de feligrana con assa y tapador de plata de feligrana bale sessenta y quatro rs. de plata, 64 rs.

- ottro barro garrafilla de chile pintada con guarnizion y tapador de feligrana bale beinte y quatro rs. de platta, 24 rs.

- ottro barro de chile de bocados con pie, assas de plata lissa bale beinte y quatro rs. de plata, 24 rs.

- ottro barro cantatico de chile agallonado con pie, dos assas y tapador de plata lissa bale sessenta y quatro rs. de plata, 64 rs.

- ottro barro ollita de chile con pie calado y listas de plata lissas bale treinta y dos rs. de plata, $32 \mathrm{rs}$.

- ottro barro de chile con guarnizion y lazos de feligrana de plata bale quarenta rs. de plata, 40 rs.

- ottro barrito de chile con listas de plata graneteadas bale doze rs. de plata, 12 rs.

- otro barrito calderilla de chile con assa y bozel de plata diez y seis rs. de plata, $16 \mathrm{rs}$.

- una calderilla de batro de chile con pie assa todo de feligrana de plata bale quarenta rs. de plata, 40 rs.

- un barrilito de chile con listas de plata graneteadas bale doze reales de plata, 12 rs.

- una salvilla aobada de barro de Guadalaxara guarnezida de memsrias de filigrana de plata bale zinquenta y seis rs. de plata, 56 rs.

- una castaña de barro de Guadalaxara con listas y dos rossas de platta lissa bale beinte y quatro rs. de plata, 24 rs.

- un pajaro de barro de chile con pie, alas y cola de plata de feligrana bale sesenta y quatro rs. de plata, $64 \mathrm{rs}$. 